\title{
A RADIOGRAHIC STUDY OF THE THIRD MOLAR INGLUSION
}

\author{
Nagy-Bota Monica Gristina1, Păcurar Mariana2, Hălmaciu loana', Suciu Bogdan-Andreî' , Brînzaniuc Klara'
}

${ }^{1}$ UMFST Târgu Mureș, Department M1, Târgu Mureș, Romania

${ }^{2}$ UMFST Târgu Mureș, Department MD1, Târgu Mureș, Romania

\author{
Monica-Cristina Nagy-Bota \\ Gh. Marinescu, 38, \\ Târgu Mureș, Mureș \\ email:nagy.monica@yahoo.com
}

\begin{abstract}
Objective: The aim of this study is to determine the incidence of inclusion of lower and upper third molar in the population of Mures county.

Materials and Methods: For this study, we examined the orthopantomograms (OPGs) of 243 patients (including 138 women and 105 men, aged 19-57 years old) who had impacted third molars and who presented to three Orthodontic Clinics in Tîrgu Mureș between 2015-2017. All impacted third molars were taken into consideration but which at the same time presented fully developed roots. We excluded from the study patients with pathological condition or craniofacial syndromes such as cleidocranial dysostosis and Down syndrome.

Results: In both women and men, the most common cases were of one impacted molar (61,72\%), then two $(27,16 \%)$ and three $(11,12 \%)$ impacted molars. Based on the evaluation of all radiographs, 363 impacted teeth were observed, with a higher proportion in women (54,27\%) compared to men (45,73\%). With regard to the location of the impacted teeth in the mandible or the maxilla, in both female and male patients, the incidence of mandibular impactions was higher (62,25\%) than in the maxilla $(37,75 \%)$. Regarding the link between the position on the arch (right and left side) and the localization of the impacted teeth, in female patients we can assert that while the mandible had the largest number of impacted teeth on the right side( $69,35 \%)$, the impacted teeth in the maxilla were more numerous on the left side $(60,27 \%)(p=0,00004)$. In male patients, regardless of whether the impactions were in the mandible or in the maxilla, they were more frequent on the right side (70,58\% in mandible and 76,56\% in maxilla) than on the left one.

Conclusions

1. The incidence of impacted wisdom teeth is higher in females compared to males.

2. Impacted wisdom teeth are more common on lower arch than on upper arch.

3. In female patients, the prevalence of impaction is higher on the right side in the mandible and on the left side in the maxilla

4. In male patients, the prevalence of impaction on the right side is higher in both mandible and maxilla
\end{abstract}

Keywords: mandible, impacted third molar, maxilla

\section{Introduction}

Dental impaction is a pathological state of a tooth, in which a tooth is not able to emerge in a normal position. In this case, it can be treated with the help of a dental treatment. The most commonly impacted tooth is the third molar. Pericoronitis, dentigerous cyst formation, root resorption, periodontitis can appear also in case of an impacted tooth, which can lead to decay of the adjacent teeth.(1)

Even if the frequency of impacted teeth among individuals varies from country to country, the third molar remains the most common tooth affected by impaction, followed by the maxillary canine. (2) Factors that can influence dental impaction can be systemic and local. Among the local factors we can mention the lack of space on the arch, the premature loss of deciduous teeth, the ectopic position of the dental bud, obstructions 
along the path of the eruption, dental crowding or cystic tumours. General factors include heredity, congenital syphilis, rickets, malnutrition and more serious diseases such as cleidocranial dysostosis, progeria or palatal clefts (3).

Impacted wisdom teeth can be diagnosed due to the symptoms they cause, namely, pressure, pain or swelling of the region. They can also be identified by a direct examination or visualization, and last but not least by a routine dental radiography.(4)

\section{Material and method}

For this study, panoramic radiographs (OPG) of 243 patients aged 19-57 years old, including 138 women and 105 men, were examined, who presented at three Orthodontic Clinic from Mures County. All impacted wisdom teeth were taken into consideration but which at the same time presented fully developed roots. We excluded from the study patients that were less than 19 years of age, with any anomaly, dental-alveolar pathological condition or craniofacial syndromes such as cleidocranial dysostosis, Down syndrome. The OPGs that could not provide concrete data were excluded. On the panoramic radiographs we examined the presence and degree of impacted wisdom teeth, their angulations and position as well as the possible lesions of the impacted molars and the adjacent molars. In the calculations the CHIsquared test was used. The calculations were performed using the Excel CHITEST function in the Microsoft Office Package. Statistical indicators were calculated using the DATAAnalysis mode, the optional installed module of the same program, Excel.

\section{Results}

Of the total patients whose radiographs were studied, the percentage of women was $56.8 \%$ and of men was $43.2 \%$. In both women and men, the most common cases were of one impacted molar $(61,72 \%)$, then two $(27,16 \%)$ and three $(11,12 \%)$ impacted molars $(\mathrm{p}=0,0374524)($ Table 1$)$.
Table 1. The number of impacted molars by sex

\begin{tabular}{|l|c|c|c|}
\hline $\begin{array}{l}\text { No. of impacted molars } \\
\mathrm{p}=0.0374524\end{array}$ & Males & Females & Total \\
\hline 1 & 56 & 94 & 150 \\
\hline 2 & 37 & 29 & 66 \\
\hline 3 & 12 & 15 & 27 \\
\hline Total & 105 & 138 & 243 \\
\hline
\end{tabular}

Based on the evaluation of all radiographs, according to Table 2, 363 impacted teeth were observed, with a higher proportion in women $(54,27 \%)$ compared to men $(45,73 \%)$.

Table 2. The number of impactions on both jaws in females and males

\begin{tabular}{|l|c|c|c|}
\hline $\begin{array}{l}\text { Distribution of } \\
\text { impacted teeth }\end{array}$ & Males & Females & Total \\
\hline Mandible & 102 & 124 & 226 \\
\hline Maxilla & 64 & 73 & 137 \\
\hline Total & 166 & 197 & 363 \\
\hline
\end{tabular}

This table also indicates that, with regard to the location of the impacted teeth in the mandible or the maxilla, in both female and male patients, the incidence of mandibular impactions $(62,25 \%)$ was higher than in the maxilla $(37,75 \%)$. We obtained a statistically significant result $(p=0,0119)$ regarding the link between the position on the arch (right and left) and the localization of the impacted teeth, as it can be seen in Table 3.

Table 3. The number of impactions on both sides of the jaws

\begin{tabular}{|l|c|c|c|}
\hline $\begin{array}{l}\text { Area of the jaw } \\
\mathrm{p}=0,0119712\end{array}$ & Mandible & Maxilla & Total \\
\hline Right side & 158 & 78 & 236 \\
\hline Left side & 68 & 59 & 127 \\
\hline Total & 226 & 137 & 363 \\
\hline
\end{tabular}

Figure 1 includes the localization of arch impactions in female patients, and we can assert that while the mandible has the largest number of impacted teeth on the right side( $69,35 \%)$, the impacted teeth in the maxilla are more frequent on the left side $(60,27 \%) \quad(p=0,00004)$. In male patients, regardless of whether the impactions are in the mandible or in the maxilla, they are more frequent on the right side $(70,58 \%$ in mandible and $76,56 \%$ in maxilla) than on the left one (Figure 2). 


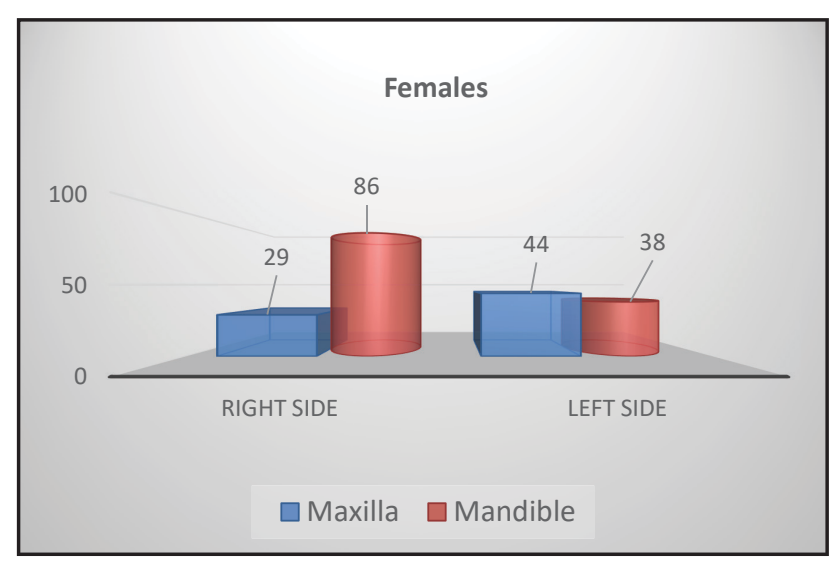

Figure 1. Distribution of impaction in females regardind the side of the impaction

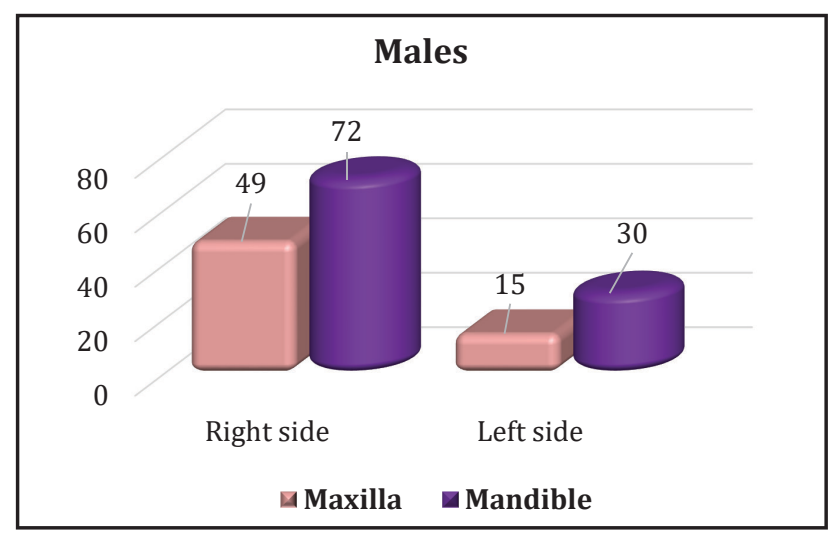

Figure 2. Distribution of impaction in males regarding the side of the impaction

\section{Discussions}

The most common tooth affected by dental impaction is the lower third molar. The etiology of impacted third molar has been discussed over time by various authors (5). Wisdom molar impaction its a common problem which affects a large part of the world's population. We can assert based on this study that the prevalence of impacted wisdom teeth is higher in women than in men, a result reported differently by some studies (Muhamad et al.) and reported similarly by a study in South-eastern Iran $(1,5)$. This higher incidence of impaction in females can be as a consequence of the stopping growth of both jaws before the third molar erupts, unlike in men, where the jawbones continue to grow even during the molar eruption, thus creating the space required to align the tooth on the arch. However, there are also many authors who believe that there is no gender predilection regarding these impactions $(6,7)$. As a result of this present study, we conclude that impactions were more frequent on the inferior arch compared to the upper arch, which is in agreement with a similar study that showed an increased incidence of impacted wisdom molar in lower arch compared to the upper one (8). With regard to the number of impacted teeth, we can state from our study that most patients had only one impaction, following cases with two or three dental impactions, similar results also reported by other authors $(9,10)$. Some studies have reported a large difference in incidence among impaction cases in the urban and rural populations, because of a dental arch shortening due to a possible atrophy as a consequence of industrialization and food processing. Thus, the incidence of such impactions and malocclusions was highlighted among the populations of industrialized nations in North America and Europe $(9,11)$. Also in this study, we obtained a statistically significant result with respect to the frequency of impactions on right/left part of the arch, therefore it is higher on the right side compared to the left one, both in men and in women, except for cases of impactions on the maxillary arch in women where these are more frequent on the left side. While some studies show that impactions appear more frequently on the left side $(5,12)$, others report a higher frequency on the right side (13). About the impacted teeth, it is interesting that some previous studies reported no differences between the position of the impacted molar in term of the left or right side of the arch $(1,8,14)$.

\section{Bonclusions:}

1. Impacted wisdom teeth are more common in women compared to men.

2. Impacted wisdom teeth are more common on lower arch than on upper arch.

3. In female patients, the incidence of impaction is higher on the right hemi-arch of the lower jaw and on the left hemi-arch of the maxilla.

4. In male patients, the prevalence of impaction on the right side is higher in both mandible and maxilla 


\section{References}

1. Hashemipour MA,Tahmasbi-Arashlow M, Fahimi-Hanzaei F. Incidence of impacted mandibular and maxillary third molars: a radiographic studyin a Southeast Iran population.med oral Patol Oral Cir Bucal.2013; 18(1):e140-5.

2. Hassan Al-Zoubi, Abdulgader Abdullatif Alharbi, Donald J.Ferguson, Muhammad Sohail Zafar. Frequency of impacted teeth and categorization of impacted canines:A retrospective radiographic study using orthopantomograms. Eur JDent.2017;11(1):117-121.

3. Singh M, Chakrabarty A. Prevalence of Impacted Teeth: Study of 500 Patients. International Journal of science and Research(IJSR);2016, 1(5): 1577-1580.

4. Dodson TB, Susarla SM. Impacted wisdom teeth. BMJ Clin Evid.2010; 2010:1302.

5. Muhamad AH, Watted N. Prevalence of Impacted Mandibular Third Molars in Population of Arab Israeli: A Retrospective Study. IOSR Jornal of Dental and Medical Sciences(IOSR-JDMS).2016; 1(15): 80-89.

6. Kumar VR, Yadav P, Kashu E, Girkar F, Chakraborty R. Prevalence and Pattern of Mandibular Third Molar Impaction in Eritrean Population: A Retrospective Study. J Contemp Dent Pract. 2017;18(2): 100-106.

7. Lima CJ, Silva LC, Melo MR, santos TS. Evaluation of the agreement by examiners according to classification of third molars. Med Oral Patol Oral Cir Bucal 2012; 17(2): e281-e286.

8. Al-Anqudi SM, Al-Sudairy S, Al-Hosni A, Al-Maniri A. prevalence and Pattern of Third Molar Impaction: A retrospective study of radiographs in Oman. Sultan Qaboos Univ Med J. 2014; 14(3): e388-92.

9. Šečić S, Prohić S, Komšić S,Vuković, A. Incidence of impacted mandibular third molars in population of Bosnia and Herzegovina: a retrospective radiographic study. Journal ofHealth Sciences.2013; 3(2):151-158. Doi: 1017532/jhsci.2013.80.

10. Hassan AH. Pattern of third molar impactions in a Saudi population. Clinical, Cosmetic and
Investigational Dentistry. 2010; 2: 109-113.

11. Olasoji HO, Odunsaya SA. Comparative study of third molar impaction in rural and urban areas of South-western Nigeria. Odonto- Stomatologie Tropicale. 2000; 90:25-29.

12. Gupta S, Bhowate RR, Nigam N, Saxena S. Evaluation of impacted mandibular third molars by panoramic radiography. ISRN Dent.doi:10.5402/2011/406714.

13. Deshpande P, Guledgud MV, Patil K. Proximity of Impacted Mandibular Third Molars to the Inferior Alveolar Canal and Its Radiographic Predictors: A Panoramic Radiographic Study. J Maxillofac Oral Surg 12: 145-151.

14. Hatem M, Bugaighis I, Taher ME. Pattern of third molar impaction in Libyan population: A retrospective radiographic study. The Saudi Journal for Dental Research. 2016;1(7): 7-12. 